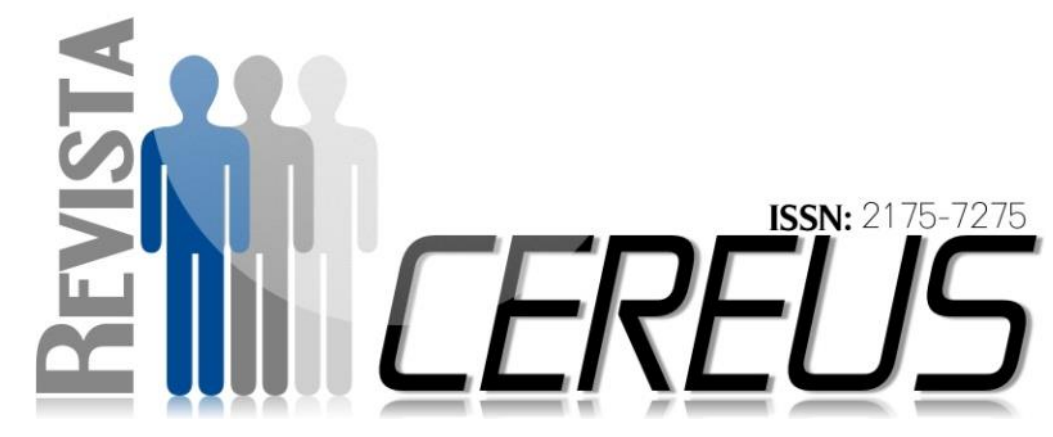

DOI: 10.18605/2175-7275/cereus.v9nep232-249.

\title{
A MEDIAÇÃO DO NOVO CÓDIGO DE PROCESSO CIVIL COMO INSTRUMENTO DE ROMPIMENTO DA ALIENAÇÃO PARENTAL
}

CONCEIÇÃO, Lorena Lopes ${ }^{1}$

RESUMO

FURLAN, Fernando Palma Pimenta ${ }^{2}$

O presente artigo, sem a pretensão de esgotar o relevante tema, trata da alienação parental seu processo histórico, partindo de uma análise de como a mesma se desenvolveu perante a sociedade, a medida que ressalta também as formas de identificação da alienação parental e como a mediação pode ser utilizada para romper esses conflitos de cunho familiar, evitando que esses problemas cheguem até o judiciário. A partir das orientações do método dedutivo, a presente pesquisa jurídica busca o estudo da síndrome da alienação parental, os efeitos psicológicos em casos de ocorrência, dando ênfase na mediação prevista no Novo Código de Processo Civil como instrumento de resolução pacífica da divergência entre os genitores. A alienação parental está cada vez mais recorrente no seio familiar, tendo em vista que, com a mudança da sociedade e o crescimento

\footnotetext{
${ }^{1}$ Aluna do curso de direito do Centro Universitário Unirg

${ }^{2}$ Docente do curso de direito do Centro Universitário Unirg
} 
dos divórcios, os pais têm dificuldade de aceitar a separação e acabam transmitindo os problemas que ocorreram entre marido e mulher para seus filhos, instigando-os para que os mesmos se posicionem do lado de um dos genitores. Neste ínterim acabam por denegrir a imagem do outro genitor para os menores, incorrendo na prática da alienação parental, punível com o afastamento perante os infantes, dentre outras consequências.

Palavras-chave: Alienação parental. Separação judicial. Mediação. Solução de conflitos. Psicologia jurídica.

\section{THE MEDIATION OF THE NEW CODE OF CIVIL PROCEDURE AS AN INSTRUMENT OF BREAKDOWN OF PARENTAL DISPOSAL}

\section{ABSTRACT}

This article, without the pretension of exhausting the relevant theme, deals with parental alienation in its historical process, starting from an analysis of how it has developed before society, as well as the ways of identifying parental alienation and how to Mediation can be used to break these family conflicts, preventing these problems from reaching the judiciary. Parental alienation is increasingly recurrent within the family, given that with the change of society and the growth of divorces, parents have difficulty accepting separation and end up conveying the problems that have occurred between husband and wife for their children, Instigating them so that they stand on the side of one of the parents. In the meantime they end up denigrating the image of the other parent to the minors, incurring in the practice of parental alienation, punishable by the removal of infants, among other consequences. From the guidelines of the deductive method, the present legal research seeks the study of the parental 
alienation syndrome, the psychological effects in cases of occurrence, emphasizing the mediation provided in the New Code of Civil Procedure as an instrument for peaceful resolution of the divergence between the parents.

Key Words: Parental alienation. Judicial separation. Mediation. Conflict resolution. Legal psychology.. 


\section{INTRODUÇÃO}

É visível nas famílias constituídas por pais e filhos, a submissão dos infantes aos conflitos que ocorrem entre seus pais, pois 0 divorcio é um período de difícil adaptação para todos, e principalmente para os infantes que se veem perdidos em meio a tal conflito, onde ambas as partes estão emocionalmente abalada.

É justamente nesse período de conflito que o pai ou a mãe se vê no direito de atrapalhar a relação entre a criança e o outro genitor que não ficou com a guarda, a fazendo acreditar ter sido abandonada por ele no momento em que decide se separar do mesmo. A

\section{METODOLOGIA}

Esta pesquisa se desenvolveu através do uso do método descritivo, analisando os fatos e fenômenos jurídicos decorrentes do referido tema, expondo a mediação como instrumento de rompimento da alienação parental. Vários procedimentos metodológicos foram utilizados, iniciando através da pesquisa teórica, onde foram citados muitos doutrinadores respaldados por amplo conhecimento jurídico sobre a matéria relatada, através da publicação isso dá-se o nome de alienação parental.

Com o surgimento do Novo CPC, acredita-se que a mediação pode vir a ser um forte instrumento na diminuição dessa prática de alienação parental, já que as partes, por meio de um diálogo, têm a oportunidade de por fim ao conflito.

A priori a pesquisa teve 0 objetivo de analisar se a mediação pode ser considerada, como um meio eficaz de solução de conflitos da alienação parental, no qual milhares de crianças estão sendo vítimas nos dias atuais.

textos e informativos sobre o referido tema, bem como leis do Congresso Nacional sancionadas para efetivar a segurança jurídica atinente à temática.

Nas pesquisas realizadas, após abordagem de temas diversos, todos os argumentos foram construídos para um melhor entendimento e compreensão científica acerca da temática proposta.

A pesquisa desenvolvida tem natureza qualitativa, pois foram citados 
vários estudiosos e doutrinadores especialistas na área estudada.

\section{DESENVOLVIMENTO}

\subsection{PARTES HISTÓRICAS}

No que tange ao progresso dos métodos consensuais de solução de conflitos, é importante frisar que, nos primórdios da sociedade, quando se notaram os riscos e danos da autotutela, direcionou-se a solução dos conflitos a terceiros, que agiam como facilitadores, para que se chegasse ao consenso.

Responsabilizava-se a essa função um indíviduo de renome na comunidade - sacerdote, cacique, ou o próprio rei - e se realizava a pacificação, evitando, assim, a busca pela "justiça". Sabe-se que a igreja católica também contribuiu para mediar os conflitos que existiam entre os seus fiéis, bem como a mediação criminal e a familiar.

Com o passar do tempo, a solução de conflitos por meio de recursos que valorizem o diálogo e a compreensão entre as partes ganharam maior espaço no Direito brasileiro. Pois, somente mais tarde, quando o Estado assumiu todo seu poder, nasceu o processo judicial - que tem objetivo de solucionar conflitos existentes entre determinadas partes.

O conceito de família sempre esteve profundamente interligado ao casamento que, naquela época, era baseado em um princípio de conservadorismo no qual a mulher e seu esposo jamais se separavam. No qual, ainda, as igrejas repudiavam a dissolução dos matrimônios. De acordo com o entendimento de Washington de Barros Monteiro:

Pelo casamento cria-se um
vínculo jurídico entre os
cônjuges, que está contida a
sociedade conjugal, que
importa a comunhão de vidas,
nos aspectos espiritual, social,
físico e, por vezes, de
patrimônios, a depender do
regime de bens em vigor no
casamento. (MONTEIRO,
2011, p.323).

No ano de 1889, com a Proclamação da República, aconteceu a separação definitiva entre a Igreja e o Estado, que passou a regular o casamento, fazendo com que o Brasil se tornasse um país laico.

Somente no Código Civil de 1916, apresentou-se o "desquite", pelo qual se admitia o rompimento da sociedade conjugal, mas não o vínculo. 
A sociedade conjugal poderia ser restabelecida a qualquer tempo, mediante simples petição ao juiz.

No entanto, as pessoas desquitadas não poderiam contrair novo casamento, apesar de já não existirem mais deveres conjugais e a incomunicabilidade patrimonial. Porém, tal restrição não impedia a constituição de novos vínculos afetivos, ou seja, as chamadas "famílias clandestinas", que sempre foram foco de grande preconceito e rejeição social.

Com a publicação da Lei do Divórcio (Lei 6.515/77), surge um novo momento na evolução histórica da dissolução do casamento. Manifestase, portanto, na normatização brasileira, o sistema binário de dissolução da sociedade e do vínculo. Com a introdução do divórcio, a lei passou a exigir que os cônjuges se separem, para depois converter a separação em divórcio. (NETO, 2015, p.01)

Com a Constituição de 1988, as pessoas passaram a ser mais essenciais do que seus bens materiais, sendo assim, eliminou o caráter que impedia a separação, retirando o lapso temporal que antes era necessário cumprir, para então se adquirir o divórcio.

\subsection{ALIENAÇÃO PARENTAL}

A prática do ato da alienação parental tem sido cada vez mais recorrente. Sua origem está relacionada à intensificação das estruturas de convivência familiar. Deste modo, quando da separação dos genitores, passou a ocorrer entre os mesmos uma disputa pela guarda dos filhos, algo que não acontecia anteriormente, pois, geralmente, os filhos ficavam sob a guarda da mãe. Ao pai cabia somente o direito de visitas em dias pré-determinados, normalmente em fins de semana alternados.

Através da mediação, há a possibilidades de evitar a prática da alienação parental, pois as famílias podem, através da consulta ao mediador, resolver seus problemas sem que estes precisem chegar ao judiciário.

\section{Maria Berenice Dias ao} comentar acerca da alienação parental dentro de determinada família, elucida:

Muitas vezes a ruptura da vida
conjugal gera na mãe
sentimento de abandono, de
rejeição, de traição, surgindo
uma tendência vingativa muito
grande. Quando não consegue
elaborar adequadamente o luto
da separação, desencadeia um
processo de destruição, de
desmoralização, de descrédito
do ex-cônjuge. Ao ver o Rev. Cereus, v. 9, n. esp, p.232-249, ago-dez./207, UnirG, Gurupi, TO, Brasil. 
interesse do pai em preservar a convivência com o filho, quer vingar-se, afastando este do genitor. Para isso cria uma série de situações visando a dificultar ao máximo ou a impedir a visitação. Leva o filho a rejeitar o pai, a odiá-lo. (DIAS, 2006)

psiquiatra americano Richard Gardner nominou de "síndrome de alienação parental":

Programar uma criança para
que odeie o genitor sem
qualquer justificativa. Trata-se
de verdadeira campanha para
desmoralizar o genitor. O filho
é utilizado como instrumento
da agressividade direcionada
ao parceiro. A mãe monitora o
tempo do filho com o outro
genitor e também os seus
sentimentos para com ele. A
criança, que ama o seu genitor,
é levada a afastar-se dele, que
também a ama. Isso gera
contradição de sentimentos e
destruição do vínculo entre
ambos. Restando órfão do
genitor alienado, acaba
identificando-se com o genitor
patológico, passando a aceitar
como verdadeiro tudo que lhe é
informado. (GARDNER,
APASE)

Como se percebe, pode-se dizer que a alienação parental é uma consequência da dissolução da relação conjugal dos pais, em que o cônjuge que tem a guarda da criança, geralmente a mãe, incute no menor a ideia de que o outro genitor não o ama.

Como esclarece Maria Berenice Dias, o genitor alienador acaba por assumir um total controle sobre a criança, de modo que o outro genitor acaba afastando o infante cada vez mais do segundo genitor.

O possuidor da guarda, ao destruir a relação do filho com o outro genitor, assume o controle sob a criança no qual se tornam completamente inseparáveis, passando o pai a ser considerado um agressor do lar, um intruso que deve ser afastado de qualquer maneira do convívio com o filho. (RICARTI, 2011, p.02)

\subsection{CONFLITOS}

O Código Civil de 2002, no seu artigo. 1576 cc, diz que "a separação judicial põe termo aos deveres de coabitação e fidelidade recíproca, e ao regime de bens". Porém, não põem fim aos deveres de assistência e respeito entre os separados que, na maioria das vezes, tiveram filhos nos seus relacionamentos e merecem toda uma atenção especial, para que não sejam prejudicados com a decisão dos pais. (BRASIL, CC/2002)

Através do divórcio surge a disputa pela a guarda dos filhos que ficará com um dos genitores, e este terá que ter sua visita regulamentada, pagar pensão de caráter alimentar, entre outras obrigações que vão surgindo com o crescimento da criança. 
No entanto, a realidade do judiciário não é tão simples como deveria ser, pois os pais se envolvem muito emocionalmente, o que acaba afetando totalmente a maioria dos divórcios, trazendo conflitos de cunho pessoal para ser resolvido pelo o juiz, o que acarreta uma super lotação de ações judiciais que são desnecessárias, pois poderiam ser resolvidas amigavelmente entre as partes.

Nota se que, na maioria das separações e divórcios, a disputa pela a guarda dos filhos comporta violências, abusos e alienações envolvendo os menores. Em razão disso, o judiciário tem resolvido os conflitos com muita cautela ao decidir com qual dos genitores ficará a guarda dos filhos, pois uma decisão equivocada pode causar imensurável transtorno ao infante.

Denise Maria Peressini explica bem essa questão da psicologia jurídica na área do processo judicial brasileiro:

Nas Varas de Família e das Sucessões dos Foros Regionais e dos Tribunais de Justiça estaduais, priorizam-se casos em que há filhos envolvidos (direta ou indiretamente) nas relações processuais. Isso porque, como membro da família afetivamente mais sensível, a criança percebe mais facilmente os efeitos nocivos de uma desestruturação familiar, e por esse motivo sofre os maiores prejuízos emocionais comportamentais.

(PERESSINI, 2003, p.52)

Os casais chegam às varas de família com problemas de cunho pessoal, sem a intenção de resolvê-los de forma pacífica, o que torna os casos ainda mais difíceis, pois sempre estão com o emocional abalado. Denise Maria Peressini diz:

Que a busca para soluções dos conflitos trazidos ao Judiciário irá ampliar o trabalho do psicólogo judiciário, para verificar fatos e ajudar a resolver os problemas com o seu laudo, tratando a família como sistema, verificando a maneira de sua estruturação e como os seus membros se relacionam, a família é vista como um grupo de pessoas ligadas entre si por parentesco, afeto, solidariedade, necessidade de reprodução, como forma de garantir sua identidade social. (PERESSINI, 2003, p 62)

\subsection{A SÍNDROME DA ALIENAÇÃO}

PARENTAL NA DISPUTA DA GUARDA

Com base no que foi demonstrado até o decorrer do presente artigo, verifica-se que os divórcios judiciais e as disputas de guarda ocasionam muitos problemas para os pais e, principalmente, para os filhos que, em decorrência da situação que vivenciam, podem desencadear a síndrome da alienação parental. 
A síndrome foi definida pela primeira vez nos Estados Unidos por Richard Gardner em 1987, com o passar do tempo se difundiu na Europa em 2001, surgindo mais tarde um interesse na área de psicologia e do direito que tinha por finalidade "aplicar os conhecimentos oriundos da Psicologia no campo jurídico com o intuito de estudar o comportamento humano no âmbito das relações das pessoas com a Justiça". (ROSA, 2008, p.11)

A alienação parental é o processo de programar uma criança para que ela odeie o seu outro genitor, fazendo uma espécie de lavagem cerebral de forma a desmoralizar o mesmo.

Com a facilidade que se tornou 0 processo de divórcio atualmente, a mulher passou a ter mais liberdade no seu agir e com um tempo maior para dedicar a outras atividades, que não fossem aquelas voltadas ao lar. Em decorrência dessa situação, as disputas pela guarda dos filhos se tornaram comum nos Tribunais.

François Podevyn esclarece que, normalmente, a síndrome irá se manifestar principalmente no ambiente da mãe, por conhecer historicamente que a mulher é a mais indicada para exercer a guarda dos filhos. (PODEVYN, 2001)

Continua o mesmo estudioso:

A Síndrome se manifesta, em geral, no ambiente da mãe das crianças, notadamente porque sua instalação necessita muito tempo e porque é ela que tem a guarda na maior parte das vezes. Todavia, pode se apresentar em ambientes de pais instáveis, ou em culturas onde tradicionalmente a mulher não tem nenhum direito concreto. (PODEVYN, 2001)

Passa-se ao estudo dos efeitos e consequências advindas da prática de alienação parental.

\subsection{EFEITOS E CONSEQUENCIAS}

O único prejudicado com a alienação parental é a própria criança, pois ao ser levada a odiar o outro genitor, perde um vínculo muito forte e importante com seu pai ou mãe, conforme for o caso, trazendo, assim, enormes e prejudiciais consequências para si e para um dos genitores que, geralmente, é outra vitíma na história.

Jorge Trindade define que essa síndrome vai também gerar uma identificação com 0 abuso $e$ negligência, até os maltrato e abuso infantil:

A Síndrome de Alienação Parental tem sido identificada como uma forma de negligência contra os filhos. Para nós, entretanto, longe de pretender provocar dissensões terminológicas de pouca 
utilidade, A Síndrome de Alienação Parental constitui uma forma de maltrato e abuso infantil. (TRINDADE, 2007, $p$ 113)

Podem ser provocados outros efeitos nas crianças, dependendo da idade, personalidade, devendo ser levado em consideração, ainda, o vínculo afetivo que aquela possuía com seu genitor. Os sintomas que aparecem geralmente são: ansiedade, insegurança, medo, isolamentos, depressão, entre outros. Em razão de toda a situação os filhos ficam muito vulneráveis.

A instigação da alienação parental em criança é considerada um comportamento abusivo que pode ser comparado ao abuso sexual e físico, pois não é somente o genitor alienado que irá sofrer as consequências, e sim todos aqueles que fazem parte da vida e cotidiano da criança, pois a criança acaba privada de conviver com a outra parte da família, que também é uma referência para a sua formação.

\subsection{A IDENTIFICAÇÃO PELO O} JUDICIARIO DA SINDROME DA ALIENAÇÃO PARENTAL

Quando 0 judiciário toma conhecimento da síndrome da alienação parental ele deve adotar medidas que zelem pela a proteção do menor. Fazendo uso da Constituição Federal de 1988, Código Civil, e Estatuto da Criança e Adolescente, decidindo de imediato para que a criança não seja tão prejudicada.

Nota-se que o conflito entre genitores trará uma reação diferente em cada criança, sendo necessário que cada uma possua avaliações individuais. É o que afirma Jorge Trindade: "De fato, a Síndrome de Alienação Parental exige uma abordagem terapêutica especifica para cada uma das pessoas envolvidas, havendo a necessidade de atendimento da criança, do alienador e do alienado."

Podevyn conceitua bem esses conflitos com uma explicação sobre a identificação da síndrome:

Para identificar uma criança
alienada, é mostrada como o
genitor alienador confidencia a
seu filho seus sentimentos
negativos e às más
experiências vividas com o
genitor ausente. Dessa forma,
o filho vai absorvendo toda a
negatividade que o alienador
coloca no alienado, levando-o
a sentir-se no dever de
proteger, não o alienado, mas,
curiosamente, o alienador,
criando uma ligação
psicopatológica similar a uma
"folie a deux". Forma-se a
dupla contra o alienado, uma
aliança baseada não em
aspectos saudáveis da
personalidade, mas na
necessidade de dar corpo ao
vazio. (PODEVYN, 2001,
APASE)


Com a promulgação da Lei da Alienação Parental 2.318, de 26 de agosto de 2010, é possível que o magistrado intervenha desde o inicio para interromper a alienação parental, pois a criança não pode ficar sendo prejudicada pelo seu genitor.

Há três estágios da síndrome, são eles: leve, médio e grave.

No leve, as visitas ainda se
apresentam calmas, algumas
dificuldades na troca do
genitor, e enquanto o filho está
com o genitor alienado, as
manifestações para a
desmoralização são mais
discretas. (GARDNER3, \$20
apud VALÉRIO, 2016, p.02)

Já no estágio médio, "os argumentos usados são absurdos, pois o alienador é completamente mau e o outro completamente bom surge problemas com as visitas, o comportamento das crianças passa a ser inadequado." (GARDNER, §27 y 28 apud VALÉRIO, 2016, p. 02)

Por fim, no estágio grave, o autor diz que os filhos estão muito perturbados, e acabam ficando paranóicos. Acabam ficando em pânico somente com a ideia de ter que ver o outro alienado, tendentes a explosões de violências, ocorre fortes campanhas de desmoralização do alienado, o vinculo fica seriamente prejudicado. (VALÉRIO, 2016, p.02)

\subsection{PSIQUIATRIA FORENSE}

Gustavo Torres leciona:

A psiquiatria forense atua nos casos em que haja qualquer dúvida sobre a integridade ou a saúde mental dos indivíduos, em qualquer área do Direito, buscando esclarecer à justiça se há ou não a presença de um transtorno ou enfermidade mental e quais as implicações da existência ou não de um diagnóstico psiquiátrico. (TORRES, 2016, p.01)

Denise Maria define essa profissão do psicólogo que integra esse grupo de profissionais:

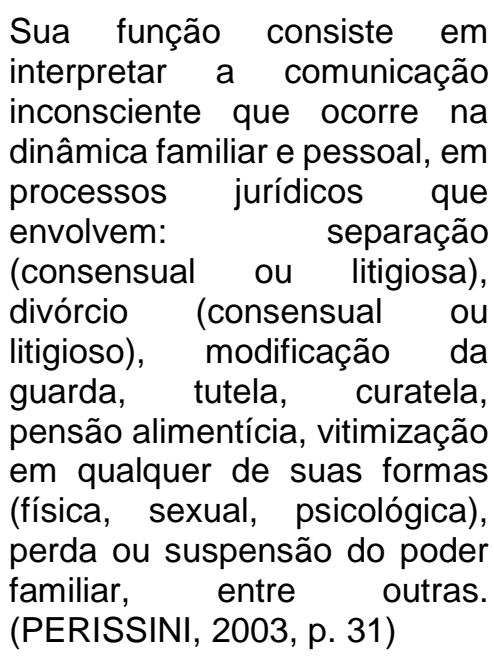

É notório que este trabalho desenvolvido por psicólogo não faz parte da cultura brasileira, pois geralmente estes médicos se concentram em desenvolver sua atividade em clinicas, e não como assessor do judiciário.

\subsection{AOS ADVOGADOS E O PODER JUDICIARIO}


Como foi demonstrado no decorrer do presente artigo, quando se identifica a síndrome da alienação parental, o Poder Judiciário tem o dever de evitar o seu desenvolvimento, porém o que se percebe é que ainda se tem muita dificuldade em se identificar e sanar esses conflitos causados pela a alienação parental.

Priscila Maria (2006) afirma que: "Via de regra, até por falta de adequada formação, os juízes de família fazem vistas grossas a situações que, se examinadas com um pouco mais de cautela, não se converteriam em exemplos do distúrbio ora analisado."

Os juízes têm a função tomar as devidas providências para que 0 problema não se perdure no tempo. Priscila Maria enumera as diversas solução a serem tomadas:

[...] a) ordenar a realização de terapia familiar, nos casos em que o menor já apresente sinais de repulsa ao genitor alienado; b) determinar $o$ cumprimento do regime de visitas estabelecido em favor do genitor alienado, valendose, se necessário, da medida de busca e apreensão; c) condenar o genitor alienante ao pagamento de multa diária, enquanto perdurar a resistência às visitas ou à prática que enseja a alienação; d) alterar a guarda do menor, principalmente quando 0 genitor alienante apresentar conduta que se possa reputar como patológica. (FONSECA, 2007, p. 82)
3.9 NOÇÕES PRELIMINARES E CONCEITO DE MEDIAÇÃO

Fernanda Tartuce assim conceitua a mediação:

Mediar é facilitar a
comunicação entre as pessoas
para propiciar que estas
próprias possam, a partir de
uma compreensão ampliada
dos meandros da situação
controvertida, engendrar
respostas conjuntas sobre as
questões relevantes do
conflito. (TARTUCl, 2008)

Com base nesses aspectos é necessário entender que a mediação vem apresentando ser um importante método de resolução de conflitos, por ser capaz de possibilitar à pessoa humana a preservação de sua dignidade e do respeito.

Para que a mediação surta seus efeitos é necessário que se desenvolva um diálogo para que sejam compreendidas as necessidades e dificuldades de cada parte envolvida no conflito. Durante a sessão de mediação, o mediador - terceiro neutro à disputa - funcionará como um facilitador de todo esse processo de restauração da comunicação, a partir da aplicação de técnicas apropriadas, entabuladas através de conhecimentos interdisciplinares.

A pessoa que vai ser o mediador observa o conflito, e extrai dele os principais pontos que serão relevantes 
para que ele proporcione uma possível solução para aquele determinado conflito.

Como já salientamos em outra passagem, na mediação as partes trazem os problemas periféricos que, geralmente, não estão diretamente relacionados ao conflito que as partes inicialmente buscam resolver. É nessa medida que a mediação proporciona uma resolução real do conflito - pois abrange questões centrais e satélites que afligem 0 relacionamento das partes dissidentes - e, por conseguinte, previne futuras demandas. (SILVA, 2013, p. 163)

O novo Código de Processo Civil

trouxe, no seu art 175, uma previsão expressa à mediação extrajudicial, reconhecendo que a mesma tem a possibilidade de resolver os conflitos do inicio ao final do processo.

A pessoa que vai ser o mediador observa o conflito e extrai dele os principais pontos que serão relevantes para que ele proporcione uma possível solução para aquele determinado conflito.

Na mediação as partes trazem os problemas periféricos que, geralmente, não estão diretamente relacionados ao conflito que as partes inicialmente buscam resolver. É nessa medida que a mediação proporciona uma resolução real do conflito - pois abrange questões centrais e satélites que afligem 0 relacionamento das partes dissidentes - e, por conseguinte, previne futuras demandas. (SILVA, 2013, p. 163)
O novo Código de Processo Civil trouxe, no seu art. 175, uma previsão expressa a respeito da mediação extrajudicial, reconhecendo que a mesma tem a possibilidade de resolver os conflitos do inicio ao final do processo.

Art. 175 CPC. As disposições desta Seção não excluem outras formas de conciliação e mediação extrajudiciais vinculadas a órgãos institucionais ou realizadas por intermédio de profissionais independentes, que poderão ser regulamentadas por lei específica. Parágrafo único. Os dispositivos desta Seção aplicam-se, no que couber, às câmaras privadas de conciliação e mediação.

Art. $165 \S 2^{\circ} \quad$ CPC $\quad$ conciliador, que atuará preferencialmente nos casos em que não houver vínculo anterior entre as partes, poderá sugerir soluções para o litígio, sendo vedada a utilização de qualquer tipo de constrangimento ou intimidação para que as partes conciliem.

$\S 3^{\circ}$ O mediador, que atuará preferencialmente nos casos em que houver vínculo anterior entre as partes, auxiliará aos interessados a compreender as questões e os interesses em conflito, de modo que eles possam, pelo restabelecimento da comunicação, identificar, por si próprios, soluções consensuais que gerem benefícios mútuos.

Ante a relevância do tema, necessária uma análise do instituto da mediação no Novo CPC.

Rev. Cereus, v. 9, n. esp, p.232-249, ago-dez./207, UnirG, Gurupi, TO, Brasil. 
3.10 A MEDIAÇÃO NO NOVO CODIGO DE PROCESSO CIVIL

O novo código de processo civil trata de uma forma especial a mediação e seus conciliadores, demonstrando tamanha importância que estes possuem para um bom andamento da justiça. Trazendo ainda a promoção, "a qualquer tempo, a autocomposição, preferencialmente com auxílio de conciliadores e mediadores judiciais". Ou seja, os juízes iram utilizar de forma alternativa os mediadores a fim de alcançar a efetividade processual. (art. 139, inc. V, $\mathrm{CPC})$

O Conselho Nacional de Justiça utiliza a mediação, através da resolução $\mathrm{n}^{-}{ }^{0} 125$ de 2010, que estabelece diretrizes básicas para a prática consensual de solução de conflitos visando dar incentivo às práticas alternativas de dirimir controvérsias, este regramento no art. 40 incumbe ao próprio CNJ o dever de "organizar programa com o objetivo de promover ações de incentivo à autocomposição de litígios e à pacificação social por meio da conciliação e da mediação". (CNJ, 2010)

A resolução reconhece, no art. 6on, V., a importância de serem ofertadas disciplinas de formação e aperfeiçoamento em técnicas consensuais de solução de conflitos, tanto em instituições de ensino públicas, quanto privadas, além das escolas de magistratura com vistas à propagação de uma cultura de pacificação social. (CNJ, RES. № 125/2010).

É de suma importância ressaltar que os Tribunais devem garantir a preparação e atualização de forma continua a seus operadores em técnicas modernas e efetivas de dirimir conflitos, como assim estabelece o art. $7^{\circ}$, V. "instalar Centros Judiciários de Solução de Conflitos e Cidadania que concentrarão a realização das sessões de conciliação e mediação que estejam a cargo de conciliadores e mediadores, dos órgãos por eles abrangidos" (CNJ, RES. № 125).

José Roberto Neves Amorim comenta 0 uso das práticas consensuais nos últimos anos:

Entre 2011 e 2013, foram
criados os primeiros núcleos de
práticas consensuais de
resolução de conflitos, ao todo
são 100 CEJUSCS, 44 na
capital de São Paulo e 56 no
litoral e interior do Estado,
tendo competência nas áreas
cível, fazenda pública,
previdenciária, família e
Juizados Especiais Cíveis. $[\ldots]$ 
Uma pesquisa realizada pelo Tribunal de Justiça do Estado de São Paulo mostrou que na fase pré-processual houve um aproveitamento nas causas cíveis e de família de $70 \%$ no ano de 2012 e $74 \%$ no ano de 2013. Já na fase processual o proveito foi de $69 \%$ em 2012 e $85 \%$ em 2013. Esses números provam o bom rendimento que os núcleos puderam proporcionar aos jurisdicionados como também

\section{CONSIDERAÇÕES FINAIS}

A partir dos textos levantados, ficou evidente que durante as relações familiares têm-se afeto e respeito mútuo, porém o que se percebe é que quando os relacionamentos se dissolvem os conjugues se aproveitam do conflito para assim prejudicar o outro genitor praticando a alienação parental e afastando o infante do seu genitor.

Com isso a síndrome da alienação parental é um tema atual e que deve ser analisado com toda seriedade, pois a família é uma instituição que possui todo apoio na Constituição Federal devendo ser protegida e amparada pelo o judiciário quando necessário.

Foi possível observar no decorrer das pesquisas que a síndrome da alienação parental pode acarretar várias sequelas na vida das crianças tais como: depressão crônica, a expansão deste método, reafirmando sua eficácia (AMORIM, 2014, pp. 01-10).

Das ponderações feitas pelo citado autor, tem-se que o uso das ferramentas consensuais se mostra favorável nos últimos anos, apesar de ainda haver muito em que se aprimorar.

transtornos, sentimento de isolamento, dupla ou múltipla personalidade, entre outras. E que muito desses sentimentos pode acompanhar na formação do caráter da criança perdurando até a vida adulta. Porém, foi demonstrado que através da mediação é possível solucionar esses problemas sem que os mesmo tenham que chegar até o judiciário.

Com um capitulo próprio no novo código de processo civil a mediação é de suma importância para dirimir conflitos que envolva a alienação parental, pois como foi apresentada no presente artigo a mediação através de pessoa neutra e imparcial irá mostrar o melhor caminho para se solucionar determinado conflito, sem que seja necessário procurar 0 judiciário, evitando com isso o excesso de processos nas varas de famílias. 


\section{REFERÊNCIAS}

AMORIM, José Roberto Neves. Conciliação é a solução rápida e eficaz para o atendimento da população. 26 de fevereiro de 2014 . Disponível em:<http://www.tjsp.jus.br/Download/Conciliacao/Nucleo/NupemecDoTJSP.pdf.

Acesso em: 03 de agosto de 2016;

BARROS, Renata Furtado de; LARA, Paula Maria Tecles. Justiça e democracia: as novas perspectivas da hermenêutica constitucional. Disponível em: $<$ https://books.google.com.br/books?id=k7QpCgAAQBAJ\&pg=PA225\&lpg=PA225\&d $\mathrm{q}=\mathrm{a}$ +ordenar+a+realiza\%C3\%A7\%C3\%A3o+de+terapia+familiar,+nos+casos+em+q ue+o+menor+j\%C3\%A1+apresente\&source=bl\&ots=vs0whNEalE\&sig=Jf9Hijk1dYYFINDwtXKF78cg2w\&hl=pt-

BR\&sa=X\&redir esc=y\#v=onepage\&q=ORDENAR\%20A\%20REALIZA\%C3\%87\%C3 \%830\&f=false $>$. Acesso em 30 out. 2016;

BRASIL. Lei $n^{\circ}$. 10.406 de 10 de janeiro de 2002. Código Civil Brasileiro. Presidência da República. Disponível em: < https://www.planalto.gov.br/ccivil_03/_ato20152018/2015/lei/l13105.htm >. Acesso em 10 out. 2016;

BRASIL. Lei $\mathrm{n}^{\circ}$. 11.238, de 26 de agosto de 2010 . Dispõe Dispõe sobre a alienação parental e altera 0 art. 236 da Lei o 8.069, de 13 de julho de 1990. Presidência da República. Disponível em: $<$ http://www.planalto.gov.br/ccivil 03/ ato2007-2010/2010/lei//12318.htm>. Acesso em 20 out. 2016;

BRASIL. Lei $\mathrm{n}^{\circ}$. 13.105 de 16 de março de 2015. Código de Processo Civil. Presidência da República. Disponível em: <https://www.planalto.gov.br/ccivil_03/_ato2015-2018/2015/lei/13105.htm>. Acesso em 10 out. 2016;

CNJ, Conselho Nacional da Justiça. Resolução n ${ }^{\circ} 125$ de 29 de novembro de 2010. Disponível em: < http://www.cnj.jus.br/busca-atos-adm?documento=2579 >. Acesso em 20 de out. 2016;

DIAS, Maria Berenice. Síndrome da Alienação Parental o que é isso? Publicado em APASE 2006, Disponível em: <http://www.apase.org.br/94013-berenice.htm>. Acesso em 04 nov. 2016;

NETO, Inácio de Carvalho. As mudanças da Nova Lei do Divórcio em matéria de Dissolução do Casamento. Genjurídico, 14 de out. 2015. Disponível em: < http://genjuridico.com.br/2015/10/14/as-mudancas-da-nova-lei-do-divorcio-emmateria-de-dissolucao-do-casamento/>. Acesso em 25 out. 2016;

PEREIRA, Tânia da Silva. O Direito de Família e os desafior no Novo Còdigo Civil. Revista Justitia.

Disponível em: $<$ http://www.revistajustitia.com.br/artigos/27556b.pdf >. Acesso em 26 out. 2016; 
PODEVYN, François (04/04/2001). Tradução para Português: Apase - Associação de Pais e Mães Separados (08/08/2001): Associação Pais para Sempre: disponível em http://www.paisparasemprebrasil.org, acesso em 23.03.2008;

PODEVYN, François. Síndrome de Alienação Parental. Publicado em 04/04/2001. Tradução para Português. APASE - Associação de Pais e Mães Separados (08/08/2001): Associação Pais para Sempre: Disponível em: <http://www.apase.org.br/94001-sindrome.htm>. Acesso em: 25 out. 2016;

RICARTE, Olívia. Alienação parental: quando feridas abertas se recusam a cicatrizar; o papel do judiciário na proteção da saúde psíquica do menor. In: Âmbito Jurídico, Rio Grande, XIV, n. 94, nov 2011. Disponível em: <http://www.ambitojuridico.com.br/site/index.php?n link=revista artigos leitura\&artigo id=10659>.

Acesso em nov. 2016;

ROSA, Felipe Niemezewski. A síndrome de alienação parental nos casos de separações judiciais no direito civil brasileiro. Monografia. Curso de Direito. PUCRS, Porto Alegre, 2008. Disponível em $<$ https://sites.google.com/site/alienacaoparental/textos-sobresap/felipe_niemezewski.pdf>, acesso em 01 nov. 2016;

SILVA, Denise Maria Peressini da. Psicologia jurídica no processo civil brasileiro: a interface da psicologia com direitos nas questões de família e infância,São Paulo: Casa do Psicólogo, 2003. Disponível em: $<$ https://books.google.com.br/books?id=mXUCdhiHGh8C\&pg=PP5\&hl=ptbr\&source= gbs selected pages\&cad=2\#v=onepage \&q=Nas\%20Varas $\% 20$ de $\% 20 \mathrm{Fam} \% \mathrm{C} 3 \% \mathrm{~A}$ Dlia\%20e\%20das\%20Sucess\%C3\%B5es\%20dos\%20Foros\%20Regionais\%20e\%20 dos\%20Tribunais\%20de\%20Justi\%C3\%A7a\%20estaduais\&f=false>. Acesso em 25 out. 2016;

TARTUCE, Fernanda. Mediação nos Conflitos Civil. Editora Método. São Paulo. 2008. Mediação no Novo CPC: questionamentos reflexivos. In Novas Tendências do Processo Civil: estudos sobre o projeto do novo Código de Processo Civil. Org.: Freire, Alexandre; Medina, José Miguel Garcia; Didier Jr, Fredie; Dantas, Bruno; Nunes, Dierle; Miranda de Oliveira, Pedro (no prelo). Disponível em www.fernandatartuce.com.br/artigosdaprofessora. Acesso em 24/03/2015;

TORRES, Gustavo. Psiquiatria Forense. Widoctor, 14 de julho de 2016. Disponível em: <http://widoctor.com.br/psiquiatria-forense/>. Acesso em 30 de out. 2016;

TRINDADE, Jorge. Incesto e alienação parental: realidades que a justiça insiste em não ver/ Maria Berenice Dias, coordenação - São Paulo, Editora Revista dos Tribunais, 2007, p113. CUENCA, José Manoel Aguilar. Artigo publicado no site da Associação de Pais e Mães Separados 
TRINDADE,Jorge. Manual de Psicologia Jurídica Para Operadores do Direito. 4aㅡ ed. verificada, atualizada e ampliada. Porto Alegre: Livraria do Advogado Editora, 2010, p. 178;

VALÉRIO, Natália A. Síndrome de alienação parental pode levar criança à depressão. O desaforado, 26 de setembro de 2016 . Disponível em: <http://www.odesaforado.com.br/2016/09/sindrome-de-alienacao-parental-podelevar-crianca-a-depressao/>. Acesso em 01 nov. 2016.

Recebido em: 17/11/2016

Aprovado em: 13/11/2017 